\title{
Structure and Stability of Au-supported Layered Cobalt Oxide Nanoislands in Ambient Conditions
}

\author{
Jakob Fester ${ }^{1}$, Zhaozong Sun ${ }^{1}$, Jonathan Rodríguez-Fernández ${ }^{1}$, Alex S. Walton ${ }^{2,3^{*}}$ and Jeppe V. \\ Lauritsen $^{1^{*}}$ \\ Interdisciplinary Nanoscience Center (iNANO), Aarhus University, 8000 Aarhus C, Denmark \\ ${ }^{2}$ School of Chemistry, University of Manchester, Manchester M13 9PL, UK \\ 3Photon Science Institute, University of Manchester, Manchester M13 9PL, UK
}

\begin{abstract}
Cobalt oxide is a promising earth-abundant electrocatalyst for water splitting, however the structural complexity of oxides coupled with the difficulty of characterizing it in its operating environment mean that fundamental understanding of its catalytic properties remains poor. In this study, we go beyond vacuum studies and investigate the morphological evolution of a $\mathrm{CoO}_{x} / \mathrm{Au}(111)$ model system from intermediate to high pressures of $\mathrm{H}_{2} \mathrm{O}$ vapor, by means of Scanning Tunneling Microscopy (STM) and Near-Ambient Pressure (NAP)- and vacuum X-ray Photoelectron Spectroscopy (XPS). At elevated $\mathrm{H}_{2} \mathrm{O}$ pressure, we describe the formation of a well-defined $\mathrm{Co}(\mathrm{OH})_{2}$ nanoisland morphology with cobalt in the $2+$ oxidation state. In contrast, the presence of $\mathrm{O}_{2}$, in air and liquid water, results in only partially hydroxylated $\mathrm{Co}^{3+}$ phases comprising sheets of $\mathrm{CoO}\left(\mathrm{OH}_{\mathrm{x}}\right)$ trilayer, corresponding to a single sheet of cobalt(III) oxyhydroxide. We conclude that the oxyhydroxide structure, known to be the catalytically active phase for the oxygen evolution reaction (OER) is stabilized by aerobic conditions, which inhibits further transformation into the catalytically inactive cobalt (II) hydroxide.
\end{abstract}

\section{Introduction}

First-row transition metal oxides $(\mathrm{Fe}, \mathrm{Ni}, \mathrm{Co})$ show great promise as earth-abundant electrocatalysts for the oxygen evolution reaction (OER) - one of the half-reactions in electrochemical water splitting. Improving the efficiency of OER electrocatalysts is a key bottleneck to the development of commercially viable electrochemical water splitting, so there has been intense activity in understanding the structure and electrocatalytic properties of these oxides ${ }^{1-3}$. However, it is becoming clear that it is critical to study these catalysts in a realistic operating environment in order to fully understand them and reveal their working principles in detail. Specifically, for cobalt and iron oxides, evidence is growing that the active phases for electrocatalysis are in fact the oxyhydroxide phases, and not the bulk crystalline oxides 4.

In the recent years, significant efforts have therefore been devoted to application and development of surface science techniques towards feasible in situ studies of catalysts under realistic operating conditions, mainly exploiting spectroscopic techniques until now ${ }^{5-8}$. For example, several oxide films, including $\mathrm{Cu}_{2} \mathrm{O}, \mathrm{MgO}, \mathrm{Si}_{2} \mathrm{O}, \alpha-\mathrm{Fe}_{2} \mathrm{O}_{3}$ and $\mathrm{Fe}_{3} \mathrm{O}_{4}$, have been investigated with Near-Ambient Pressure XPS (NAP-XPS) 9-13, revealing adsorption of molecular $\mathrm{H}_{2} \mathrm{O}$ and high levels of hydroxylation up to a monolayer coverage of $\mathrm{OH}$ on the oxide surface. In parallel, the use of Scanning Tunneling Microscopy (STM) is emerging, including demonstrations of ex-situ studies of oxide sur- faces after immersion into water bath ${ }^{14,15}$ and image acquisition of oxides in liquid environment by means of electrochemical STM ${ }^{15},{ }^{16}$. These techniques have successfully been applied to a range of thin oxide film systems supported on noble metals that are interesting for fundamental studies of model catalysts or as novel catalysts in their own right ${ }^{17-20}$.

To study the fundamental properties of cobalt oxide nanocatalysts and understand reported activity enhancement effects in combination with gold ${ }^{21,22}$, we have provided a detailed structural and spectroscopic analysis of a model system comprising crystalline $\mathrm{CoO}_{\mathrm{x}}$ nanoislands dispersed on $\mathrm{Au}(111)$ single crystals, that allows for highresolution STM studies under vacuum conditions. Common to the stable morphologies is that they exist in layered structures with alternating $\mathrm{O}$ - and $\mathrm{Co}$ sheets parallel to the substrate, terminated by the (111) facet of the rock salt structure. Although these structures are stabilized by charge transfer from the gold, they are structurally and chemically very similar to the oxyhydroxide electrocatalyst, exhibiting the same layered structure and so are studied as a model system. In the present context, we focus on the atomically thin $\mathrm{Co}-\mathrm{O}$ film, referred to as a bilayer. Throughout the text, we will also refer to the UHV prepared $\mathrm{O}-\mathrm{Co}-\mathrm{O}\left(\mathrm{H}_{0.33}\right)$ trilayer for comparison, which is stabilized by $\mathrm{H}$ on $1 / 3$ of the surface $\mathrm{O}$ basal plane atoms ${ }^{23}$. The system has previously been extensively characterized by means of STM, X-ray Photoelectron spectroscopy (XPS/XAS) and Density Functional Theory (DFT), as well 
as investigated for its fundamental interaction with low pressures of $\mathrm{H}_{2} \mathrm{O}$ and $\mathrm{O}_{2}$ in the vacuum regime ${ }^{23-27}$. The trilayer structure is a single sheet of cobalt(III) oxyhydroxide - considered the active phase for the OER. Starting with the well-defined bilayer $\mathrm{CoO}$ structure, we recently demonstrated the OER activity of the Co oxide/Au in an electrochemical setup under anaerobic conditions and provided a post-reaction analysis of the surface morphology by $\mathrm{STM}^{28}$. These studies clearly pointed to a stabilizing role of the Au that supports the formation of the active cobalt(III) oxyhydroxide phase in the alkaline electrolyte.

In this paper, we investigate the structure and composition of the $\mathrm{CoO}_{\mathrm{x}} / \mathrm{Au}(111)$ model system under the real operating environment of an OER electrocatalyst (i.e. ambient pressures with both water and oxygen present). The results show that the model system is robust against these conditions and remains in all cases in its characteristic layered morphology.

We observe that under high pressures of water vapor ( $\sim 10$ mbar) a complete transformation to the catalytically inactive cobalt(II) hydroxide structure occurs via water dissociation and incorporation of $\mathrm{OH}$ above and below the cobalt layer. However, we reveal that this hydroxide is easily transformed back into the trilayer (oxyhydroxide) structure by low-temperature annealing in an oxygen atmosphere. Surprisingly, under direct immersion of the nanoislands within a water droplet under ambient conditions (in air), the transformation to cobalt (II) hydroxide does not occur and instead the bilayer islands transform to the cobalt (III) - containing trilayer structure. This is direct confirmation that the oxyhydroxide structure is favored over hydroxide under the liquid operating conditions of cobalt oxide electrocatalysts.

\section{Methods}

The experiments were performed using an ultrahigh vacuum (UHV) chamber system comprising isolated loadlock, preparation and analysis chambers separated by valves for sample transfer. The preparation chamber was equipped with an Oxford Applied Research e-beam evaporator (model $\mathrm{EGCO}_{4}$ ) and a gas inlet system for synthesis and exposures. The analysis chamber contained an ion source for $\mathrm{Ar}^{+}$sputtering, an Aarhus-type STM ${ }^{29}$ as well as an XR5o X-ray source from SPECS Gmbh in combination with a SPECS Phoibos analyzer for X-ray photoelectron spectroscopy (XPS). The base pressure of both preparation and analsysis chamber is $1 \times 10^{-10} \mathrm{mbar}$. Au(111) single crystals (Mateck) were mounted on Ta sample plates and equipped with thermocouple wires connected at the edge of the sample for temperature readout. Clean $\mathrm{Au}(111)$ samples were obtained by repeated sputter and annealing cycles (1.5 keV Ar+ / $800 \mathrm{~K}, 15 \mathrm{~min})$. The synthesis of bilayer $\mathrm{CoO}$ was carried out by Co evaporation in $1 \times 10^{-6} \mathrm{mbar}_{2}$ and post annealing treatments according to previously described procedures ${ }^{23,26}$.

$\mathrm{H}_{2} \mathrm{O}$ and $\mathrm{O}_{2}$ exposures in the $\mathrm{UHV}$ regime (below $1 \times 10^{-}$ ${ }^{6}$ mbar) were carried out by backfilling the preparation chamber through a leak valve. An intermediate pressure was reached using a movable doser tube brought close to the sample surface (less than $1 \mathrm{~mm}$ distance) to generate a high local pressure estimated to $\sim 1 \times 10^{-4} \mathrm{mbar}$ (an order of magnitude larger than the maximum reachable chamber pressure of $1 \times 10^{-5} \mathrm{mbar}$ ). High-pressure exposures in the mbar regime were carried out by removing the sample into the loadlock and backfilling it with water vapor. Samples exposed to air were transferred to the load lock and remained in the manipulator while opening the load lock door to the laboratory air. To immerse samples into liquid water (milliQ water), crystals were transferred out of the UHV chamber in a wobble stick and covered by a droplet which was subsequently removed and the sample dried by an $\mathrm{N}_{2}$ flow.

A second vacuum chamber system was used to perform Near-Ambient Pressure (NAP)-XPS. This system was equipped with similar instrumentation for sample cleaning and preparation, a differentially pumped SPECS Phoibos 150 NAP analyzer with a 1 D Delay Line Detector (DLD) and a Specs FOCUS 500 monochromated $\mathrm{Al} \mathrm{K \alpha} \mathrm{X}$-Ray source. The system contains a SPECS "DeviSim" NAP cell which can be docked onto the analyzer and allows the study of samples in $\sim$ mbar gas pressure whilst the X-Ray gun and rest of the analysis chamber are retained in ultrahigh vacuum (base pressure of $\sim 5 \times 10^{-10} \mathrm{mbar}$ )

All XPS measurements used Al K-alpha X-ray radiation $(1486.6 \mathrm{eV})$ and the spectra were calibrated against the $\mathrm{Au}$ $4 \mathrm{f}_{7 / 2}$ peak at $84 \mathrm{eV}$. Linear backgrounds were used for background subtraction in the Co $2 \mathrm{p}$ region, whereas a polynomial was used for $\mathrm{O}$ is spectra (for a detailed discussion of baseline selection, please see the Supporting Information). $\mathrm{O}$ is spectra were deconvoluted by fitting the spectra with pseudo-Voigt line profiles (product of Gaussian and Lorentzian with a (30:70) mixing, using CASAXPS.

\section{Results}

We have compared the morphology and composition of the cobalt oxide nanoislands under four regimes of $\mathrm{H}_{2} \mathrm{O}$ pressure: "UHV regime" (defined as $<1 \times 10^{-6} \mathrm{mbar}$ ), "Intermediate pressure" ( $\left.\sim 1 \times 10^{-4} \mathrm{mbar}\right)$, high pressure (1o mbar) and immersion (sample was immersed in liquid water). Unless otherwise stated, all experiments were performed at room temperature $(295 \mathrm{~K})$.

\section{Intermediate- and high pressure of $\mathrm{H}_{2} \mathrm{O}$}

We first address the effect of elevating the pressure to an intermediate value of $\sim 1 \times 10^{-4}$ mbar water vapor. Figure 1a- 

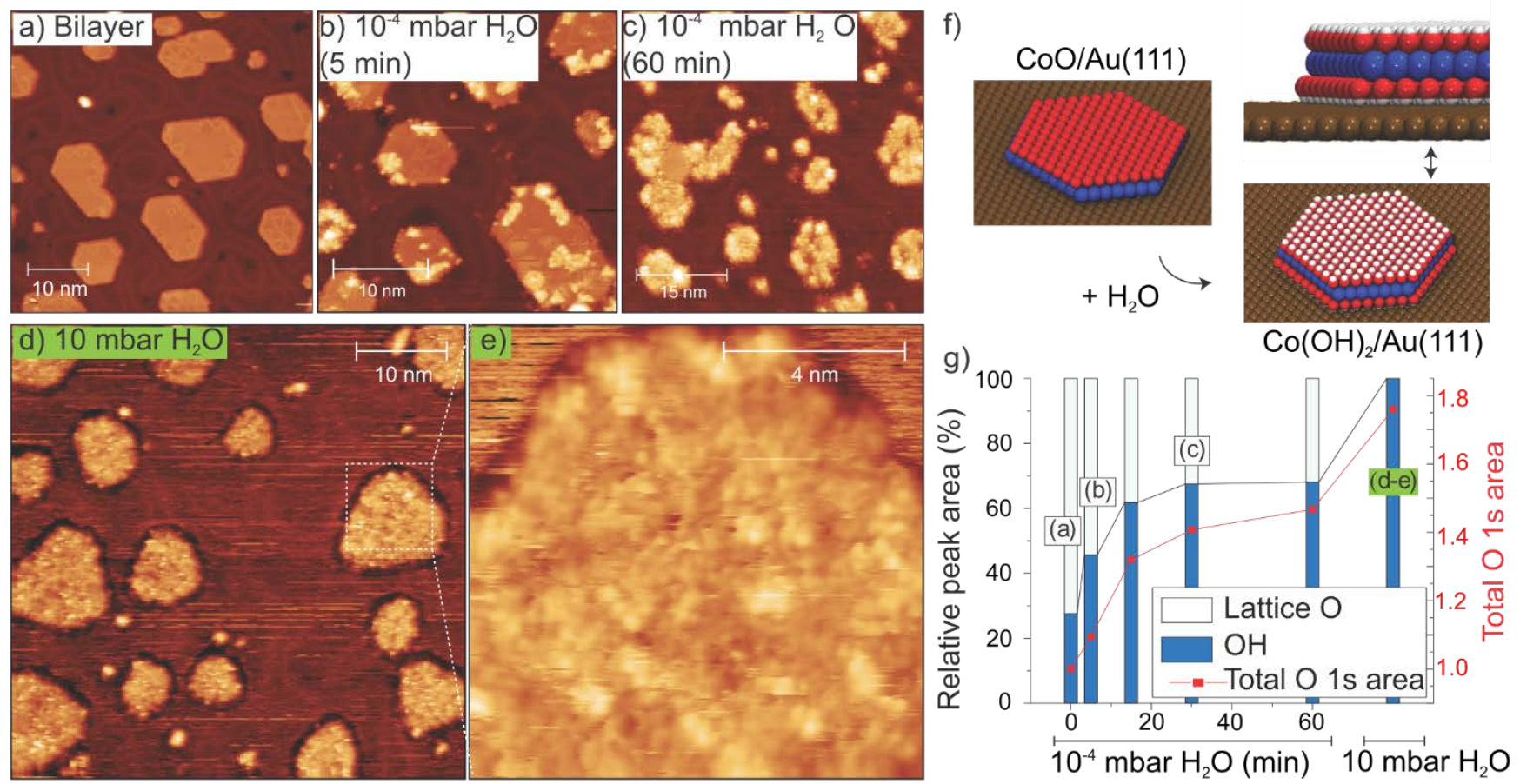

Figure 1. Exposure of bilayer to $\mathrm{H}_{2} \mathrm{O}$ at intermediate (b-c)- and high (d-e) pressure. (f) XPS O is peak area percentages (blue: OH, white: lattice O) and total normalized area (red trace). Corresponds to the samples shown in (a)-(e). (g) Sketch of the proposed $\mathrm{OH}-\mathrm{Co}-\mathrm{OH}$ hydroxide phase. Red: Oxygen, blue: Cobalt and white: Hydrogen. STM parameters in (a-c): $-1.16 \mathrm{~V} /-0.35 \mathrm{nA},-\mathbf{1 . 2 5}$ $\mathrm{V} /-0.18 \mathrm{nA}$ and $-1.23 \mathrm{~V} /-0.23 \mathrm{nA}$ and (d-e): $1.47 \mathrm{~V} / 0.17 \mathrm{nA}$ and $0.41 \mathrm{~V} / 0.38 \mathrm{nA}$.

c shows the pristine bilayer sample in STM as synthesized as well as after $5 \mathrm{~min}$ and 60 min exposure time. Figure $1 \mathrm{~d}-$ e shows bilayer sample after 10 mbar exposure. In the pristine state the $\mathrm{CoO}$ islands are characterized by hexagonally shaped islands exposing a flat (111) basal plane oriented in parallel with the $\mathrm{Au}$ substrate (see $\mathrm{CoO} / \mathrm{Au}(111)$ in Figure if). After $5 \mathrm{~min}$ exposure (Figure $1 \mathrm{~b}$ ), we observe the onset of a transformation process due to hydroxylation initiated by the appearance of areas of greater apparent height (3.7 $\pm 0.2 \AA$ vs. 1.8 $\pm 0.2 \AA$ bilayer island height at the chosen imaging conditions) located at the island edges. This process progresses further with exposure time until the bright patches almost completely cover the basal plane (Figure 1c).

By monitoring the $\mathrm{O}$ is peak in XPS, we observe evidence of an increased amount of hydroxyl $(\mathrm{OH})$ species indicated by an evolving peak located at $531.1 \mathrm{eV}$ at a separation from the main lattice oxygen component of $1.7 \mathrm{eV}$ (see Figure $1 \mathrm{~g}$ and 2a) ${ }^{30}$. The amount of $\mathrm{OH}$ present on the sample scales with exposure time, but saturates after 6o min. Furthermore, the total $\mathrm{O}$ is area - normalized to the Co $2 \mathrm{p}$ signal (red trace in Figure $1 \mathrm{~g}$ ) increases significantly to $\sim 1.45$ relative to the fresh bilayer.

Increasing the $\mathrm{H}_{2} \mathrm{O}$ vapor pressure further to $10 \mathrm{mbar}$ causes further hydroxylation, beyond the saturation point at intermediate pressure. In the XPS O is core level spectrum, we now observe one single component at $531.2 \mathrm{eV}$ corresponding exclusively to $\mathrm{OH}$, indicating that all lattice oxygen is hydroxylated (Figure $2 \mathrm{a}$ ). At the same time, the total $\mathrm{O}$ is peak area increases further to 1.76 relative to pristine bilayer. STM overview images of the sample in this state (Figure 1d) reveal homogeneous, flat islands on the $\mathrm{Au}(111)$ surface remaining in the hexagonal shape in an essentially unchanged coverage compared to the corresponding bilayer islands before the exposure. High-resolution images (Figure 1e) show a disordered surface structure at the atomic level with island edges now displaying significant deviation from the perfect straight state on pristine bilayer.

This behavior of the system at intermediate and high $\mathrm{H}_{2} \mathrm{O}$ pressure deviates from the previously described hydroxylation process in the UHV regime. The STM images revealing the onset of the process in the intermediate pressure regime (Figure $1 \mathrm{~b}$ ) show that our previous finding of edge mediated water dissociation as a crucial step in the hydroxylation process ${ }^{25}$ is still valid at the elevated pressure. However, in the UHV regime the total Ois area as function of water exposure stayed constant apart form a slight increase originating from $\mathrm{OH}$ adsorption at island edges only ${ }^{25}$.

We propose the structural model depicted in Figure if for this new phase, comprising a layered $\mathrm{OH}-\mathrm{Co}-\mathrm{OH}$ "trilayer hydroxide" (formally $\mathrm{Co}(\mathrm{OH})_{2}$ ). The oxygen content in this structure is in agreement with the measured increase in $\mathrm{O}$ is area of 1.76 by taking into account the photoelectron intensity attenuation of lower layer oxygen. The attenuation was previously determined experimentally in the case of the similar $\mathrm{O}-\mathrm{Co}-\left(\mathrm{OH}_{0.33}\right)$ trilayer $(\sim 1.8$ relative to bilayer ${ }^{27}$ ). We propose that the emerging structure at intermediate pressure (Figure $1 \mathrm{a}-\mathrm{c}$ ) is the same, however 

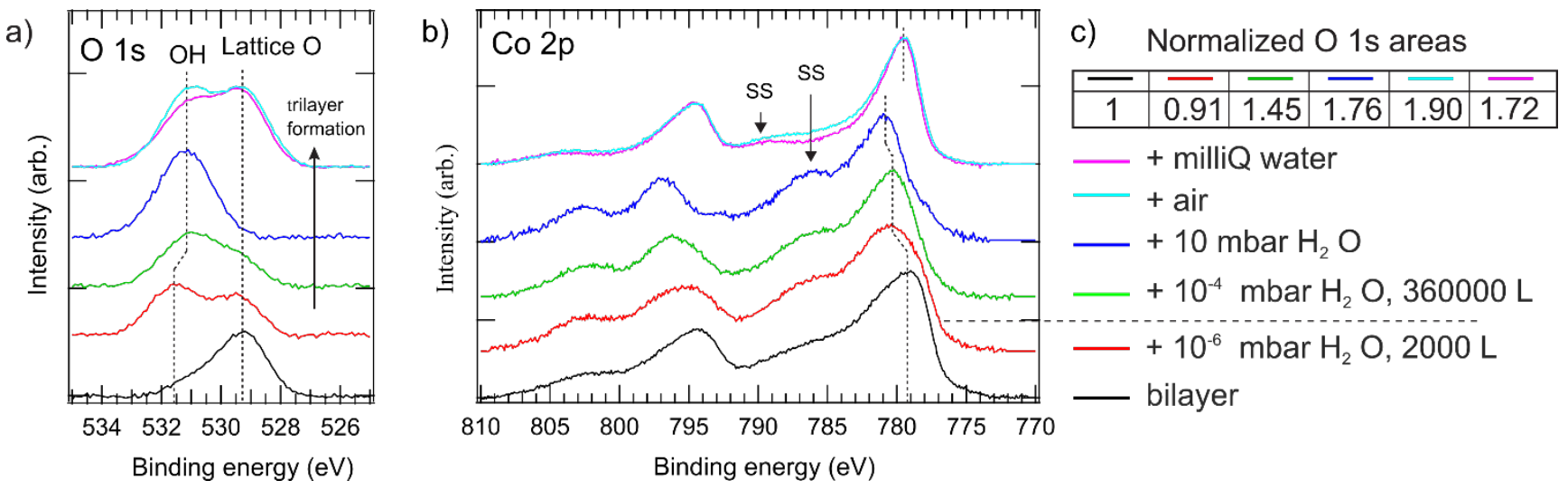

Figure 2. XPS and $\mathrm{O}$ is (a) and $\mathrm{Co} 2 \mathrm{p}$ (b) regions of bilayer exposed to increasing pressure of $\mathrm{H}_{2} \mathrm{O}$, as well as air and liquid water. The dotted line indicates the beginning of trilayer formation $\left(\mathrm{OH}-\mathrm{Co}-\mathrm{OH} / \mathrm{O}-\mathrm{Co}-\mathrm{OH}_{\mathrm{x}}\right)$ which is not observed at low $\mathrm{H}_{2} \mathrm{O}$ pressure (light blue). SS: Shakeup satellites. (c) $\mathrm{O}$ is areas normalized to the background intensity.

not reaching the full transition into pure $\mathrm{OH}-\mathrm{Co}-\mathrm{OH}$ islands due to kinetic effects.

XPS measurements were also performed to probe changes in the chemical state of oxygen species and Co in the transition from $\mathrm{Co}-\mathrm{O}$ bilayer to $\mathrm{OH}-\mathrm{Co}-\mathrm{OH}$ hydroxide (Figure $2 \mathrm{a}$ and $\mathrm{b}$ ). For comparison, we also added the spectra from a sample exposed to $2000 \mathrm{~L} \mathrm{H2O} \mathrm{(L,} \mathrm{Langmuir}=1.33 \times 10^{-}$ $6 \mathrm{mbar} \cdot \mathrm{s}$ ) at a lower water pressure of $1 \times 10^{-6} \mathrm{mbar}$. In the Co $2 p$ core level spectrum, we observe gradual changes associated with the hydroxylation towards a strong shakeup satellite (SS) and a significant main peak position shift of approximately $2 \mathrm{eV}$ to a higher binding energy of $781.1 \mathrm{eV}$. Comparing to existing X-ray photoelectron spectroscopy studies in the literature of cobalt oxide and (oxy)hydroxides, these features bear the characteristics of the $\mathrm{Co}(\mathrm{OH})_{2}$ bulk phase ${ }^{31,3^{2}}$ with the cobalt in a $\mathrm{Co}^{2+}$ oxidation state. However, we note that only the Co $2 \mathrm{p}$ spectrum after 10 mbar $\mathrm{H}_{2} \mathrm{O}$ corresponding to the fully converted $\mathrm{OH}-\mathrm{Co}-$ $\mathrm{OH}$ hydroxide exactly matches the reference spectrum of $\mathrm{Co}(\mathrm{OH})_{2}$ bulk phase.

The $\mathrm{O}$ is core level spectra evidence the increasing level of hydroxylated oxygen species $(\mathrm{OH})$ relative to the main lattice oxygen. Furthermore, the total oxygen content determined by the normalized $\mathrm{O}$ is areas (Figure $2 \mathrm{c}$ ) indicate oxygen uptake by dissociative adsorption and lattice incorporation of $\mathrm{OH}$ from $\mathrm{H}_{2} \mathrm{O}$ that results in $\mathrm{OH}-\mathrm{Co}-\mathrm{OH}$ hydroxide from intermediate pressure and upwards (indicated in Figure 2a-b by the dotted line). Another difference between samples hydroxylated in the UHV regime and at intermediate pressure is the magnitude of energy separation between the $\mathrm{OH}$ peak and main oxygen lattice components that changes from $2.0 \mathrm{eV}$ in UHV to $1.7 \mathrm{eV}$ upon formation of $\mathrm{OH}-\mathrm{Co}-\mathrm{OH}$ hydroxide at elevated pressure. We ascribe this difference to a change in chemical environment of the $\mathrm{OH}$ species the $\mathrm{OH}-\mathrm{Co}-\mathrm{OH}$ hydroxide compared to the hydroxylated bilayer at low $\mathrm{H}_{2} \mathrm{O}$ pressure (formally $\mathrm{Co}-\mathrm{OH}_{\sim 0.5}{ }^{25}$ ). The change in measured core level binding energies in XPS can be rationalized by, e.g., charge transfer mechanisms with the substrate; for instance, previous density functional theory (DFT) calculations showed that $\mathrm{Co}-\mathrm{O}$ bilayers and $\mathrm{O}-\mathrm{Co}-\left(\mathrm{OH}_{0.33}\right)$ trilayers, respectively, are stabilized charge transfer to the substrate with opposite sign ${ }^{24}$.

Since our measurements of the $\mathrm{OH}-\mathrm{Co}-\mathrm{OH}$ phase formed at high $\mathrm{H}_{2} \mathrm{O}$ pressure were conducted ex situ by transfer back into the UHV chamber for STM and XPS evaluation, we also performed Near-Ambient Pressure (NAP)XPS on Co-O bilayer/Au(111) samples at high pressures of $\mathrm{H}_{2} \mathrm{O}$ to establish that the phase in situ is in fact the same. Monitoring the progression of hydroxylation by the ratio between the $\mathrm{O}$ is lattice oxygen and $\mathrm{OH}$ components (Figure $3 a-b)$, the results show that 9 mbar $\mathrm{H}_{2} \mathrm{O}$ pressure is necessary in order to form the full hydroxide, reached at, i.e. just below our ex situ exposure pressure (10 mbar). After pumping out the $\mathrm{H}_{2} \mathrm{O}$ gas from the NAP-cell, the full hydroxide persisted and maintained an oxygen content of 1.7 relative to fresh bilayer verifying the islands are the $\mathrm{OH}$ $\mathrm{Co}-\mathrm{OH}$ hydroxide phase, as expected from the ex-situ measurements. The accompanying $\mathrm{Au} 4 \mathrm{f}$ and $\mathrm{C}$ is scans for these measurements are shown in the Supporting Information.

We also addressed the thermal stability of the OH-Co$\mathrm{OH}$ phase in a temperature programmed NAP-XPS experiment with the sample held in $\mathrm{O}_{2}$ atmosphere, ramping the temperature from $300 \mathrm{~K}$ in steps while repeatedly recording the $\mathrm{O}$ is spectrum (Figure 4a). The temperature dependent evolution revealed that the phase is only stable in 3 mbar $\mathrm{O}_{2}$ up to $420 \mathrm{~K}$. Above this temperature, we observe a loss of $\mathrm{OH}$ simultaneously with the reappearance of nonhydroxylated lattice oxygen $\left(\mathrm{O}_{\text {lattice }}\right)$. At $470 \mathrm{~K}$, the $\mathrm{O}$ is spectrum corresponds to a $50 \%$ hydroxylated phase, and the $\mathrm{Co} 2 \mathrm{p}$ spectrum at this point shows a shift from $\mathrm{Co}^{2+}$ to a $\mathrm{Co}^{3+}$ oxidation state (Figure $4 \mathrm{~b}$ ). The spectrum is very similar to that of the as-prepared $\mathrm{O}-\mathrm{Co}-\mathrm{OH}_{0.33}$ trilayer however we cannot rule out the presence of multilayer structures which contain cobalt (III) species ${ }^{23}$. In comparison, annealing the hydroxide in UHV reduced the sample 
and a metallic cobalt peak emerged in the Co $2 \mathrm{p}$ spectrum (not shown).
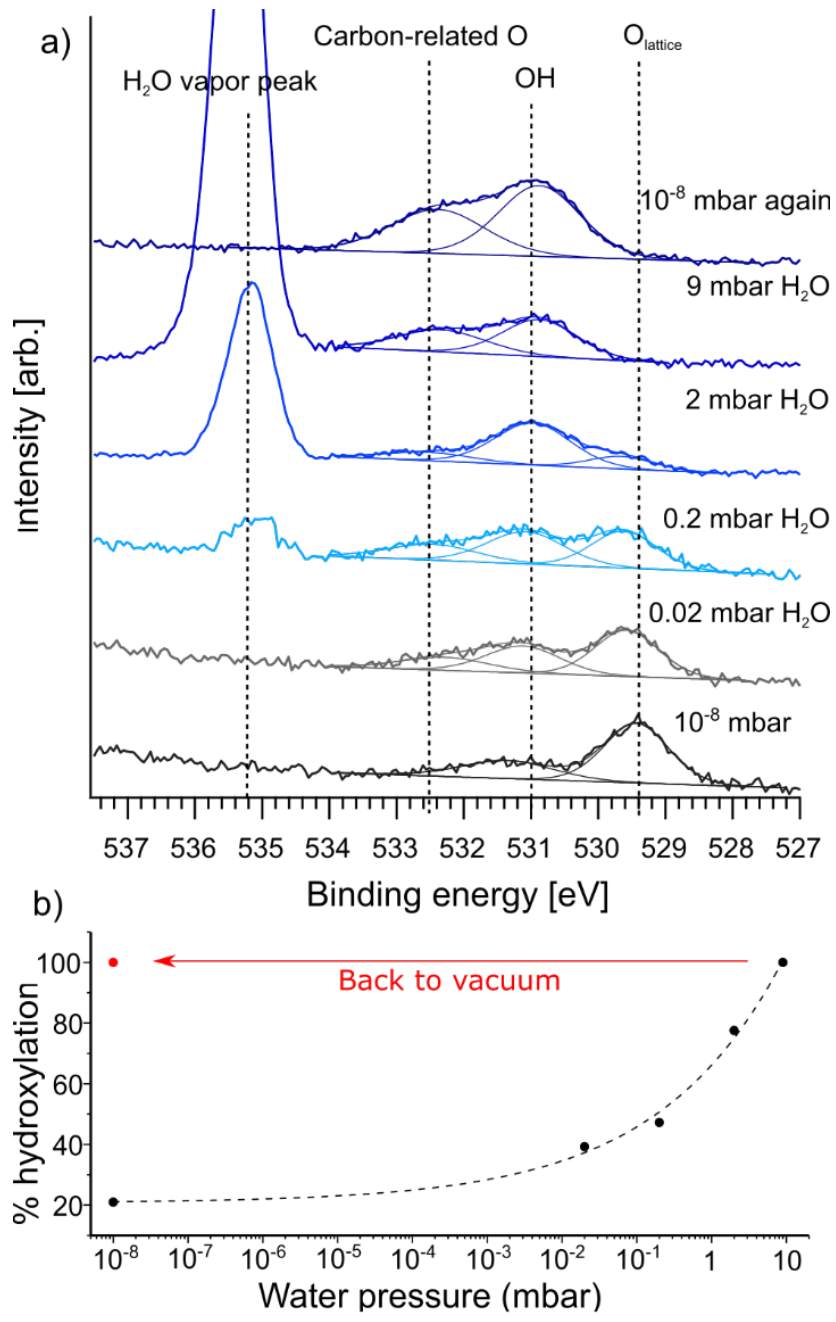

Figure 3. NAP-XPS measurements on a bilayer exposed to different pressures of water vapor. a) Ois core levels showing progressive hydroxylation as water vapor pressure increases. b) hydroxylation percentage as a function of water vapor pressure, determined from the ratio of the $\mathrm{O}_{\text {lattice }}$ to the $\mathrm{OH}$ peaks in the O1s spectrum.

\section{Air and liquid water}

STM images of bilayer samples exposed to air and after immersion in a droplet of liquid water respectively are shown in Figure 5a-b. In both cases, the islands retain their characteristic hexagonal shape, reflecting that no or very little Co redistribution or dissolution takes place. The basal planes appear disordered and no atomic resolution was obtained. However, overview images confirm the stability of the flat morphology comprising one atomic layer of cobalt.

After air exposure, the Co $2 \mathrm{p}$ spectrum (see Figure $2 \mathrm{~b}$ ) indicates a $\mathrm{Co}^{3+}$ oxidation state, evidenced by the narrow main component and the absence of the strong shakeup satellite (SS) at $\sim 786 \mathrm{eV}$ associated with $\mathrm{Co}^{+2} 33$. The total O 1s area increases to 1.90 , suggesting that the structure stabilizes in a trilayer morphology that contains cobalt in a pure $3^{+}$oxidation state ${ }^{26}$. However, the trilayer in air hydroxylates to a level that is significantly higher than for UHV prepared trilayer (see the $\mathrm{OH} /$ main component ratios in the $\mathrm{O}$ is spectra, Figure 2a). After immersion of bilayer into liquid water similar results are obtained, i.e., the cobalt is present in a $3^{+}$oxidation state and the level of hydroxylation is high compared to the $\mathrm{O}-\mathrm{Co}-\left(\mathrm{OH}_{0.33}\right)$ reference, but slightly lower as compared to the air exposed sample. We therefore suggest that the resulting structure is again a trilayer, also explaining the increase in oxygen content to 1.72 relative to bilayer (Figure 2c).
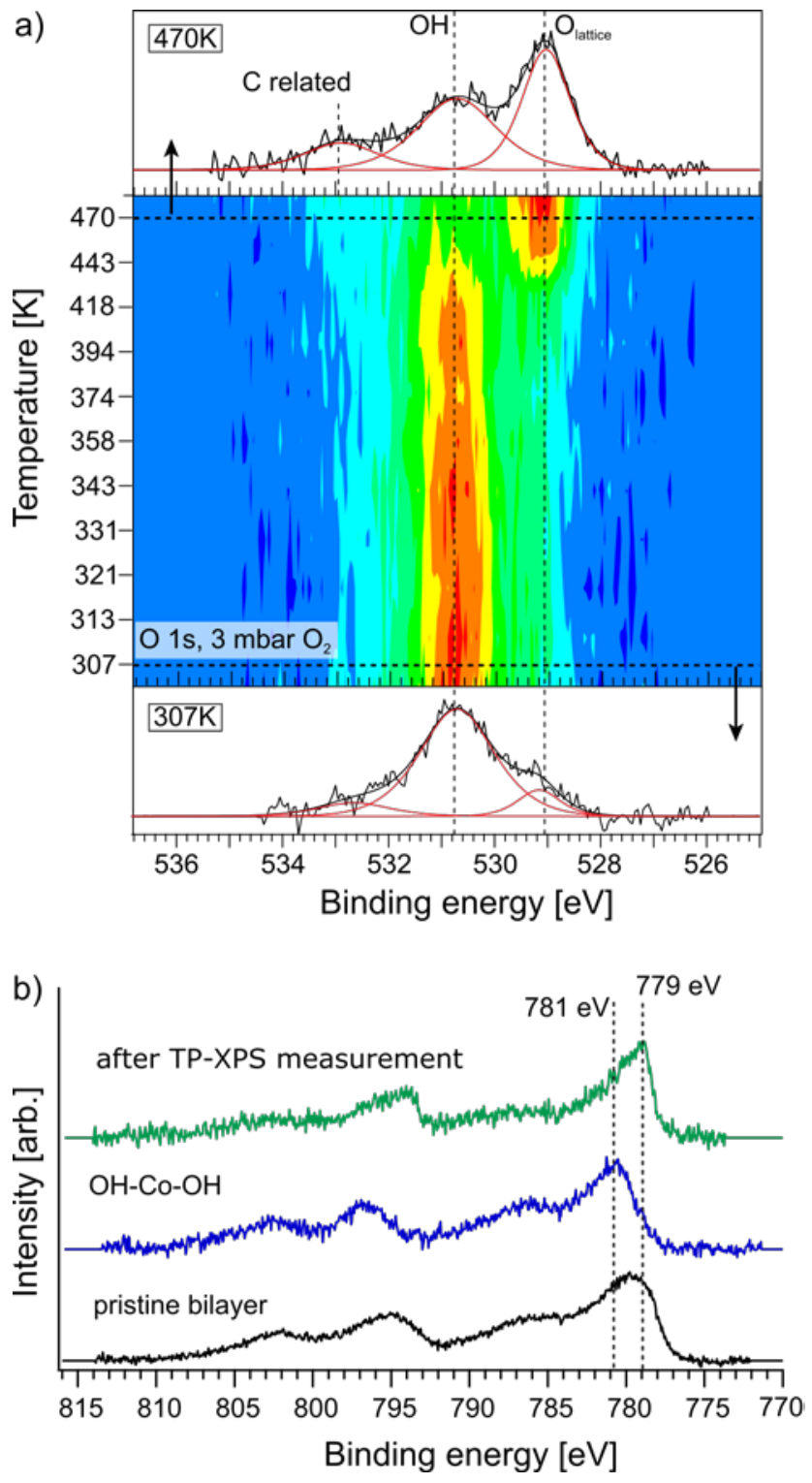

Figure 4. a) TP-XPS measurements of the O1s core level showing the removal of hydroxyls in 3 mbar of $\mathrm{O}_{2}$ upon heating. b) $\mathrm{Co} 2 \mathrm{p}$ core levels for bilayer, $\mathrm{OH}-\mathrm{Co}-\mathrm{OH}$ structure and the sample after the TP-XPS measurement in a), showing the formation of $\mathrm{O}-\mathrm{Co}-\mathrm{O}\left(\mathrm{H}_{0.33}\right)$ trilayer structures 
We summarize the effects of air and liquid water on bilayer in Figure $5 \mathrm{c}$, showing the proposed structural model of a hydroxylated O-Co-O $\left(\mathrm{H}_{\mathrm{x}}\right)$ trilayer, where $\mathrm{x}$ is close to 1 after air exposure. In line with observations of UHV prepared $\mathrm{O}-\mathrm{Co}-\mathrm{O}\left(\mathrm{H}_{0.33}\right)$ trilayer where $\mathrm{OH}$ is located on the upper basal plane and due to the facile access to this environment compared to the buried lower oxygen layer, we sketch the location of $\mathrm{OH}$ species on the top oxygen layer in Figure 5c, although distribution to the lower layer is also a possibility. It is noteworthy that we consistently observed a lower hydroxylation degree after immersion in water compared with exposure to water vapor in air. Scans of the carbon is region acquired at the same time as the Co $2 \mathrm{p}$ and $\mathrm{O}$ is scans in Figure $2 \mathrm{a}$ and $2 \mathrm{~b}$ demonstrate that exposure to air or water vapor causes a minimal increase in adventitious carbon contamination of the sample. Conversely, the liquid water exposure causes a significant increase in adventitious carbon on the surface (see Figure $\mathrm{S} 1$ ). As the transformation from $2+$ bilayer to $3+$ trilayer occurs in both air and liquid water, we conclude that adventitious carbon does not affect this transformation. However, we suggest that the presence of adventitious carbon in significant amounts in the liquid water explains the lower level of hydroxylation in these samples. Randomly physisorbed hydrocarbons, although not chemically interacting with the surface, could block the active sites for water dissociation (the island edges) and thus hinder the hydroxylation of the sample.

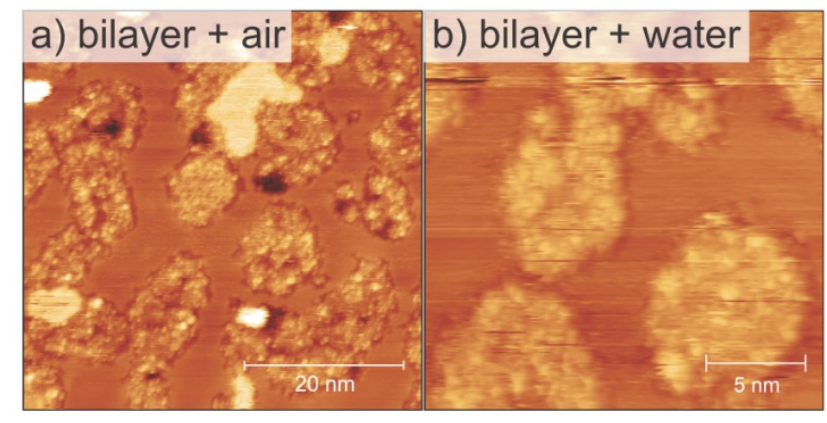

c)

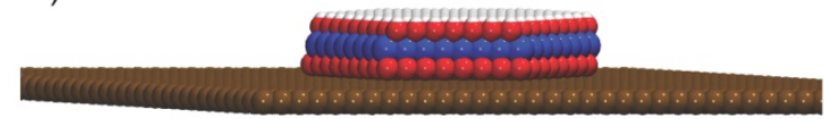

Figure 5. Bilayer exposed to air and liquid water. (a) air, 300 $\mathrm{K}$, $30 \mathrm{~min}$. (b) immersion into a droplet of liquid water, $300 \mathrm{~K}$, 30 min. (c) Proposed $\mathrm{O}-\mathrm{Co}-\mathrm{OH}_{\mathrm{x}}$ structure after both treatments, depicted with an $\mathrm{OH}$ coverage on the basal plane of $100 \%(x=1)$. Red: Oxygen, blue: Cobalt and white: Hydrogen. STM parameters in (a-b): $1.25 \mathrm{~V} / 0.19 \mathrm{nA}$ and -1.44 V/-0.15 nA.

\section{Discussion}

We demonstrate that the $\mathrm{Au} / \mathrm{CoO}_{\mathrm{x}}$ model system is robust and retains its characteristic layered structure in the real operating conditions of an OER electrocatalyst (in the presence of both water and oxygen at ambient pressures).
Our results also show that the interaction with $\mathrm{H}_{2} \mathrm{O}$ of gold-supported cobalt oxide nanoparticles depends fundamentally on the presence or absence of oxygen, leading to qualitatively different hydroxylation processes and states of the final hydroxide. We reveal that in mbar pressures of water (comparable to ambient conditions) a complete transformation to a layered cobalt(II) hydroxide is possible. However, surprisingly this transformation is only possible in the absence of oxygen. With the oxygen environment present in ambient air or in a water droplet, this transformation is inhibited in favor of transformation to the trilayer oxyhydroxide structure with the cobalt in the $3+$ oxidation state.

In principle, our water vapor-only experiments should mimic the partial pressure of water in air (the $10 \mathrm{mbar}$ used corresponds to a relative humidity of approx. $40 \%$, which is fairly typical of ambient conditions). It is therefore surprising that we do not observe the expected $100 \%$ hydroxylation in either air or liquid water. However, the presence of oxygen in both environments is an obvious factor to influence the processes. $\mathrm{O}_{2}$ constitutes $21 \%$ of laboratory air, but it also has a solubility of $6.4 \mathrm{ml} / \mathrm{L}$ at $20{ }^{\circ} \mathrm{C}$ in water 35 . We therefore specifically probed the consequence of exposing bilayer to the same $10 \mathrm{mbar}_{2} \mathrm{O}$ in a $\sim 40$ mbar $\mathrm{O}_{2}$ background. In agreement with the hypothesis of oxygen affecting the hydroxylation process, this treatment did not result in the $\mathrm{OH}-\mathrm{Co}-\mathrm{OH}$ hydroxide, but rather a $\mathrm{O}-\mathrm{Co}-$ $\mathrm{O}\left(\mathrm{H}_{0.33+\mathrm{x}}\right)$ trilayer $\left(\mathrm{Co}^{3+}\right)$, similar to UHV prepared $\mathrm{O}-\mathrm{Co}-$ $\mathrm{O}\left(\mathrm{H}_{0.33}\right)$ trilayer samples, but hydroxylated to a higher extent $(x>0.5)$, i.e. very similar to the state after exposure to air and liquid water.

The TP-XPS experiments demonstrate the full OH-Co$\mathrm{OH}$ hydroxide structure is easily converted into a cobalt (III) containing phase, most likely a $\mathrm{O}-\mathrm{Co}-\mathrm{O}\left(\mathrm{H}_{0.33}\right)$ trilayer, even in a relatively low pressure oxygen environment (3 mbar) with minimal heat input. This result adds further evidence that the presence of oxygen favors the oxyhydroxide trilayer structure over the full hydroxide. Furthermore, it suggests that conversion from $2+$ hydroxide to $3+$ oxyhydroxide is relatively facile.

In comparison to $\mathrm{CoO}$ bilayer, isostructural $\mathrm{FeO}$ thin films and nanoislands on Pt- and $\mathrm{Au}(111)$ substrates exposed to $\mathrm{H}_{2} \mathrm{O}$ only hydroxylate insignificantly, even in 10 mbar $\mathrm{H}_{2} \mathrm{O}{ }^{15}, 3^{6}$. In air and liquid water at room temperature, the FeO film on $\mathrm{Pt}(111)$ is also stable and transforms into an $\mathrm{O}-\mathrm{Fe}-\mathrm{OH}_{\mathrm{x}}$ motif ${ }^{15}$, similarly to bilayer $\mathrm{CoO}$ in the present study. However, FeO preserves its moiré structure and, again, hydroxylates to a lower level. We repeated the exposure of $\mathrm{FeO} / \mathrm{Au}(111)$ to $\mathrm{H}_{2} \mathrm{O}$ up to 10 mbar in our own laboratory for coverages similar to our experiments on $\mathrm{CoO}$ (not shown). The results are in agreement with the referenced literature and confirm a pronounced relative inertness of FeO. Furthermore, it means that the high water dissociation activity of bilayer is not only related to favorable edge sites for adsorption and dissociation, i.e. the circumstance that we study the material at coverages below 1 ML, but also directly associated with the chemical nature of cobalt, allowing facile uptake and release of both oxygen and hydroxyl groups. 


\section{Conclusions}

In summary, we probed the response of cobalt oxide bilayer islands on $\mathrm{Au}(111)$ to $\mathrm{H}_{2} \mathrm{O}$ vapor in four different pressure regions. The behavior of bilayer at elevated pressure differs significantly from the corresponding hydroxylation process studied previously in the UHV pressure regime. The effect of high water pressure on bilayer is the occurrence of spontaneous dissociative adsorption of $\mathrm{H}_{2} \mathrm{O}$, resulting in oxygen uptake, transforming it into well-defined $\mathrm{OH}-\mathrm{Co}-\mathrm{OH}$ sheets. After exposure to air or liquid water, the islands contain cobalt in the $3+$ oxidation state. This finding is surprising, given that the $\mathrm{OH}-\mathrm{Co}-\mathrm{OH}$ phase generated in the 10 mbar pure $\mathrm{H}_{2} \mathrm{O}$ environment has cobalt in the $2+$ state. However, further experiments suggested that the effect can be ascribed to the high partial pressure of oxygen in air and liquid water.

These results support that the oxyhydroxide is the stable phase in the operating environment of cobalt oxide electrocatalysts, and that it is the presence of oxygen which inhibits further transformation to the catalytically inactive cobalt(II) hydroxide. Our experiments also demonstrate that the $\mathrm{Au}(111) / \mathrm{CoO}_{x}$ system is an ideal model system to study oxygen electrocatalysis on the atomic scale as it retains the real structure of the electrocatalyst under its operating environment, but is still amenable to detailed characterization by surface science techniques.

\section{AUTHOR INFORMATION}

\section{Corresponding Author}

* Correspondence to: jvang@inano.au.dk

* Correspondence to: alex.walton@manchester.ac.uk

\section{Author Contributions}

The manuscript was written through contributions of all authors. / All authors have given approval to the final version of the manuscript.

\section{ACKNOWLEDGMENTS}

The Lundbeck Foundation and VILLUM foundation are acknowledged for financial support. ZS would like to acknowledge financial support from the Chinese Scholarship Council (CSC).

\section{Supporting Information available:}

Cis spectra recorded simultaneously with the Co $2 \mathrm{p}$ and $\mathrm{O}$ is spectra in Figure 2a-b and $3 a$ (Figure $\mathrm{S}_{1}$ and $\mathrm{S}_{2}$ ); Au $4 \mathrm{f}$ peak recorded simultaneously with Figures 2a-b, 3a and S2 (Figure $\mathrm{S}_{3}$ ); representative survey scan of a typical synthesis (Figure $\mathrm{S}_{4}$ ); example spectrum showing effects of nearby Au peak at $\mathrm{Co} 2 \mathrm{p}$ and $\mathrm{O}$ is regions (Figure $\mathrm{S}_{5}$ and $\mathrm{S6}$ ); line scans across islands shown in Figure a-d and 5a-b (Figure $\mathrm{S}_{7}$ ).

This material is available free of charge via the Internet at http://pubs.acs.org.

\section{REFERENCES}

1. Deng, X.; Tüysüz, H., Cobalt-oxide-based materials as water oxidation catalyst: Recent progress and challenges. ACS Catal. 2014, 4, 3701-3714.

2. Huang, J.; Chen, J.; Yao, T.; He, J.; Jiang, S.; Sun, Z.; Liu, Q.; Cheng, W.; Hu, F.; Jiang, Y.; et al., CoOOH Nanosheets with High Mass Activity for Water Oxidation. Angew. Chem., Int. Ed. 2015, 54, 8722-8727.

3. Liao, L.; Zhang, Q.; Su, Z.; Zhao, Z.; Wang, Y.; Li, Y.; Lu, X.; Wei, D.; Feng, G.; Yu, Q., Efficient solar water-splitting using a nanocrystalline $\mathrm{CoO}$ photocatalyst. Nat. Nanotechnol. 2014, 9, 69-73.

4. Burke, M. S.; Enman, L. J.; Batchellor, A. S.; Zou, S.; Boettcher, S. W., Oxygen evolution reaction electrocatalysis on transition metal oxides and (oxy) hydroxides: Activity trends and design principles. Chem. Mater. 2015, 27, 7549-7558.

5. $\quad$ Friebel, D.; Louie, M. W.; Bajdich, M.; Sanwald, K. E.; Cai, Y.; Wise, A. M.; Cheng, M.-J.; Sokaras, D.; Weng, T.-C.; Alonso-Mori, R., Identification of highly active $\mathrm{Fe}$ sites in $(\mathrm{Ni}$, $\mathrm{Fe}) \mathrm{OOH}$ for electrocatalytic water splitting. J. Am. Chem. Soc. 2015, 137, 1305-1313.

6. $\quad$ Wang, H.-Y.; Hung, S.-F.; Hsu, Y.-Y.; Zhang, L.; Miao, J.; Chan, T.-S.; Xiong, Q.; Liu, B., In situ spectroscopic identification of $\mu$-OO bridging on spinel $\mathrm{Co}_{3} \mathrm{O}_{4}$ water oxidation electrocatalyst. J. Phys. Chem. Lett. 2o16, 7, 4847-4853.

7. McAlpin, J. G.; Surendranath, Y.; Dinca, M.; Stich, T. A.; Stoian, S. A.; Casey, W. H.; Nocera, D. G.; Britt, R. D., EPR evidence for Co (IV) species produced during water oxidation at neutral pH. J. Am. Chem. Soc. 2010, 132, 6882-6883.

8. Zhang, M.; De Respinis, M.; Frei, H., Time-resolved observations of water oxidation intermediates on a cobalt oxide nanoparticle catalyst. Nat. Chem. 2014, 6, 362-367.

9. Deng, X.; Herranz, T.; Weis, C.; Bluhm, H.; Salmeron, M., Adsorption of water on $\mathrm{Cu}_{2} \mathrm{O}$ and $\mathrm{Al}_{2} \mathrm{O}_{3}$ thin films. J. Phys. Chem. C 2008, 112, 9668-9672.

10. Newberg, J. T.; Starr, D. E.; Yamamoto, S.; Kaya, S.; Kendelewicz, T.; Mysak, E. R.; Porsgaard, S.; Salmeron, M. B.; Brown Jr, G. E.; Nilsson, A., Autocatalytic surface hydroxylation of $\mathrm{MgO}$ (100) terrace sites observed under ambient conditions. J. Phys. Chem. C 2011, 115, 12864-12872.

11. Verdaguer, A.; Weis, C.; Oncins, G.; Ketteler, G.; Bluhm, H.; Salmeron, M., Growth and structure of water on $\mathrm{SiO}_{2}$ films on $\mathrm{Si}$ investigated by kelvin probe microscopy and in situ $\mathrm{x}$-ray spectroscopies. Langmuir 2007, 23, 9699-9703.

12. Yamamoto, S.; Kendelewicz, T.; Newberg, J. T.; Ketteler, G.; Starr, D. E.; Mysak, E. R.; Andersson, K. J.; Ogasawara, H.; Bluhm, H.; Salmeron, M., Water adsorption on $\alpha-\mathrm{Fe}_{2} \mathrm{O}_{3}$ (ooo1) at near ambient conditions. J. Phys. Chem. C 2010, 114, (5), 22562266.

13. Kendelewicz, T.; Kaya, S.; Newberg, J.; Bluhm, H.; Mulakaluri, N.; Moritz, W.; Scheffler, M.; Nilsson, A.; Pentcheva, R.; Brown Jr, G., X-ray photoemission and density functional theory study of the interaction of water vapor with the $\mathrm{Fe}_{3} \mathrm{O}_{4}$ (oo1) surface at near-ambient conditions. Langmuir 2013, 117, 27192733.

14. Hussain, H.; Tocci, G.; Woolcot, T.; Torrelles, X.; Pang, C.; Humphrey, D.; Yim, C.; Grinter, D.; Cabailh, G.; Bikondoa, O., Structure of a model $\mathrm{TiO}_{2}$ photocatalytic interface. Nat. Mater. 2017, 16, 461-466.

15. Ringleb, F.; Fujimori, Y.; Wang, H.-F.; Ariga, H.; Carrasco, E.; Sterrer, M.; Freund, H.-J.; Giordano, L.; Pacchioni, G.; Goniakowski, J., Interaction of water with $\mathrm{FeO}$ (111)/Pt (111): environmental effects and influence of oxygen. J. Phys. Chem. C 2011, 115, 19328-19335.

16. Serrano, G.; Bonanni, B.; Di Giovannantonio, M.; Kosmala, T.; Schmid, M.; Diebold, U.; Di Carlo, A.; Cheng, J.; VandeVondele, J.; Wandelt, K., Molecular ordering at the 
interface between liquid water and rutile $\mathrm{TiO}_{2}$ (110). Adv. Mater. Interfaces 2015, 2, 1500246.

17. Liu, Y.; Yang, F.; Zhang, Y.; Xiao, J.; Yu, L.; Liu, Q.; Ning, Y.; Zhou, Z.; Chen, H.; Huang, W.; et al., Enhanced oxidation resistance of active nanostructures via dynamic size effect. Nat. Commun. 2017, 8, 14459.

18. Ning, Y.; Wei, M.; Yu, L.; Yang, F.; Chang, R.; Liu, Z.; Fu, Q.; Bao, X., Nature of interface confinement effect in oxide/metal catalysts. J. Phys. Chem. C 2015, 119, 27556-27561.

19. Zhang, K.; Li, L.; Shaikhutdinov, S.; Freund, H.-J., Carbon monoxide oxidation on metal-supported monolayer oxide films: establishing which interface is active. Angew. Chem., Int. Ed. 2017, 57, 1261-1265.

20. Shaikhutdinov, S., Strong Metal-support interaction and reactivity of ultrathin oxide films. Catal. Lett. 2018, 148, 26272635 .

21. Yeo, B. S.; Bell, A. T., Enhanced activity of goldsupported cobalt oxide for the electrochemical evolution of oxygen. J. Am. Chem. Soc. 2011, 133, 5587-5593.

22. Lu, X.; Ng, Y. H.; Zhao, C., Gold nanoparticles embedded within mesoporous cobalt oxide enhance electrochemical oxygen evolution. ChemSusChem 2014, 7, 82-86.

23. Fester, J.; Walton, A.; Li, Z.; Lauritsen, J. V., Goldsupported two-dimensional cobalt oxyhydroxide $(\mathrm{CoOOH})$ and multilayer cobalt oxide islands. Phys. Chem. Chem. Phys. 2017, 19, $2425-2433$.

24. Fester, J.; Bajdich, M.; Walton, A. S.; Sun, Z.; Plessow, P. N.; Vojvodic, A.; Lauritsen, J. V., Comparative analysis of cobalt oxide nanoisland stability and edge structures on three related noble metal surfaces: Au (111), Pt (111) and Ag (111). Top. Catal. 2016, 6o, 503-512.

25. Fester, J.; García-Melchor, M.; Walton, A.; Bajdich, M.; Li, Z.; Lammich, L.; Vojvodic, A.; Lauritsen, J., Edge reactivity and water-assisted dissociation on cobalt oxide nanoislands. Nat. Commun. 2017, 8, 14169.

26. Walton, A. S.; Fester, J.; Bajdich, M.; Arman, M. A.; Osiecki, J.; Knudsen, J.; Vojvodic, A.; Lauritsen, J. V., Interface controlled oxidation states in layered cobalt oxide nanoislands on gold. ACS Nano 2015, 9, 2445-2453.
27. Fester, J.; Sun, Z.; Rodríguez-Fernández, J.; Walton, A.; Lauritsen, J. V., Phase transitions of cobalt oxide bilayers on Au (111) and Pt (111): the role of edge sites and substrate interactions. J. Phys. Chem. B 2018, 122, 561-571.

28. Fester, J.; Makoveev, A.; Grumelli, D.; Gutzler, R.; Sun, Z.; Rodríguez-Fernández, J.; Kern, K.; Lauritsen, J. V., The structure of the cobalt oxide/Au catalyst interface in electrochemical water splitting. Angew. Chem., Int. Ed. 2018, 57, 11893-11897.

29. Besenbacher, F.; Lægsgaard, E.; Mortensen, K.; Nielsen, U.; Stensgaard, I., Compact, high-stability, "thimblesize”scanning tunneling microscope. Rev. Sci. Instrum. 1988, 59, $1035-1038$.

30. Henderson, M. A., The interaction of water with solid surfaces: fundamental aspects revisited. Surf. Sci. Rep. 2002, 46, 1308.

31. Biesinger, M. C.; Payne, B. P.; Grosvenor, A. P.; Lau, L. W.; Gerson, A. R.; Smart, R. S. C., Resolving surface chemical states in XPS analysis of first row transition metals, oxides and hydroxides: Cr, Mn, Fe, Co and Ni. Appl. Surf. Sci. 2o11, 257, 27172730 .

32. Yang, J.; Liu, H.; Martens, W. N.; Frost, R. L., Synthesis and characterization of cobalt hydroxide, cobalt oxyhydroxide, and cobalt oxide nanodiscs. J. Phys. Chem. C 2009, 114, 111-119.

33. Chuang, T.; Brundle, C.; Rice, D., Interpretation of the $\mathrm{x}$-ray photoemission spectra of cobalt oxides and cobalt oxide surfaces. Surf. Sci. 1976, 59, 413-429.

34. Fester, J.; García-Melchor, M.; Walton, A. S.; Bajdich, M.; Li, Z.; Lammich, L.; Vojvodic, A.; Lauritsen, J. V., Edge reactivity and water-assisted dissociation on cobalt oxide nanoislands. Nat. Commun. 2o17, 8, 14169.

35. Weiss, R., The solubility of nitrogen, oxygen and argon in water and seawater. Deep Sea Res. Oceanogr. Abstr. 1970, 17, 721-735.

36. Deng, X.; Lee, J.; Wang, C.; Matranga, C.; Aksoy, F.; Liu, Z., In Situ observation of water dissociation with lattice incorporation at $\mathrm{FeO}$ particle edges using scanning tunneling microscopy and X-ray photoelectron spectroscopy. Langmuir 2011, 27, 2146-2149. 


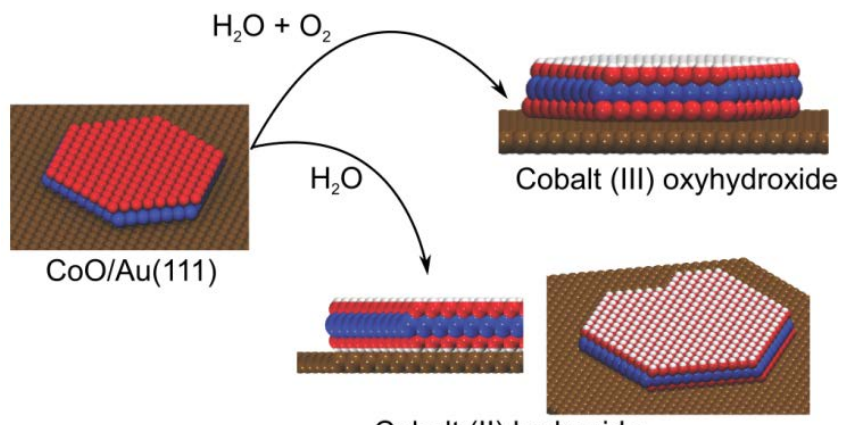

Cobalt (II) hydroxide 